\title{
Sit Smile Breathe - Seated Qigong for People with Life Changing Conditions: A Personal Reflection
}

\author{
Bernie Warren* \\ Professor Emeritus, University of Windsor, Canada
}

Submission: February 10, 2017; Published: February 15, 2017

*Corresponding author: Bernie Warren, Professor Emeritus, Drama in Education and Community, University of Windsor/ Owner, Bear Moves Mountains, 22 Mill St W, Leamington Ontario, Canada N8H 1S8, Canada, Email: merv123@uwindsor.ca

\begin{abstract}
In 1996 I watched my teacher Master George Ling Hu teach an extraordinary Seated Qigong class to a group of Seniors in Houston in which he got participants, many of whom were well over 80 , to move in ways that put my 20 year old university students to shame. As a result of this experience I began to teach Seated Qigong classes, primarily to people with life threatening and life changing conditions. What follows is a look back at Seated Qigong for people with life changing and life threatening conditions through the lens of my own teaching and research over the past 25 years.
\end{abstract}

Keywords: Health promotion; Qigong practice; Cardiac patients; Illness; Dementia; Wellness; Traditional chinese medicine; Research; Teaching; Stress reduction

\section{Setting the Scene}

My "day job", for nearly 40 years, was as an award winning teacher and researcher who held cross and inter-disciplinary positions in many different University departments. I spent my career researching the integration of evidence based Eastern \& Western best practices in Healthcare, Education \& the Arts; and, translating these best practices into easily accessible and usable concepts and skills.

All my classes, whatever course I was teaching or department I was teaching in, were infused with Eastern Philosophies and exercises that promote good health and relaxation. This was in large part because, in addition to my Western training and expertise in the performing arts and psychology, I had studied Eastern healing and martial arts from the age of 15.

Initially the exercises I taught in my performance classes were plundered mainly from Japanese approaches but within a few years, as my study of Chinese form intensified, I started to include more Chinese forms and to teach a little Tai Chi and Qigong as part of my classes. By the time I moved to Windsor in 1991, Chinese philosophies (Taoism and Buddhism) and Tai Chi and Qigong concepts and exercises, were clearly interwoven in both my teaching approach and the techniques I used.
Another Way of Seeing - Traditional Chinese Medicine and Qigong

Traditional Chinese Medicine suggests that all living things possess Chi and more than this the universe is alive with a kind of primal power and that we all live in the midst of this vital force. Chi is said to flow through meridians in the body and blockage of the flow of Chi through these meridians is believed to be one of the major causes of illness. Taoist healers believe that the correct balance between Yin and Yang and the harmonious mixture of the five elements cause health: that the relative harmony of tendencies and forces within an individual IS the individual's state of health. They contend that the 'opposite' is also true, that lack of balance and disharmony cause disease ${ }^{1}$.

Qigong is considered one of the Three Pillars of Traditional Chinese Medicine and has been used in China for hundreds of years as a primary intervention in the treatment of many medical conditions (e.g. Cancer, cardiac and respiratory problems) as well as a system of fitness and health promotion.

There are many different types of Qigong exercise. Each uses a specific posture and breathing pattern to cultivate Qi or Chi (internal energy - what in the West we might refer to as

${ }^{1}$ Klate, J.S (1980) in Warren, B. \& Coughlin, J. (2014)STAND BREATHE SMILE: Simple standing exercises and approaches to reduce stress and promote good health. Tranquility Press, Oxford, UK 
bioelectrical energy) and to stimulate oxygenation of body cells, promote hormone secretion and/or immune function.

\section{First Steps on the Path-Admitting the gap between experience and knowledge}

By late 1992, in addition to my academic movement classes, I had started teaching Qigong and Tai Chi classes for Campus Recreation. Through these classes I was introduced to The Windsor-Essex Cardiac Rehab program (WECRP), which operated in the same building, and was asked to teach a Qigong class. Participants were primarily recovering from a heart attack or stroke but others were living with debilitating conditions e.g. Lupus, Rheumatoid Arthritis. Not long after I began the classes for WECRP I was also asked to teach Qigong for The Hospice of Winds or for Cancer patients and their caregivers.

Initially, I taught what I knew, a mixture of Tai Chi and standing Qigong forms I had learned from tapes and western teachers I had encountered along the way. It didn't take me long to realize that the forms I was offering were wrong! I was Teach sets of exercises that did not make it easy for individuals to participate. The sets were too long, the exercises too strenuous, and quite frankly looking back I am not sure my sessions did not do more harm than good ... but at the time I did not know how to fix it!

In 1993 I met my current teacher Master George Ling HU. At this time I had already been studying Martial Arts and Eastern healing approaches for 25 years and I was teaching Qigong and Tai Chi as part of my academic Creative Movement classes at the University of Windsor. I learnt more from him in the first 3 hours than I had in the previous 10 years of study and practice. This meeting was the point I consider that my serious study of traditional Chinese health and martial arts began. It was not long after that I became, at least for a brief while, Master Hu's unspoken, de facto, "indoor student".

As part of my practice, during what ended up being a 10-year research project on Chinese Martial and Healing Arts, I taped our conversations in his car as we drove to these sessions. I also videotaped every session he taught and all my private lessons. I repeated this practice of taping everything almost every time I worked with him, whether at his home in Houston or at his workshop events or when he visited me in Windsor Canada. I was also awarded a small research grant which enabled me to access innumerable journals, books and videos on the subject and which I consumed voraciously.

\section{First Encounters - Seated QIGONG}

It was through Master Hu I first encountered Seated Qigong. When first I experienced this, I thought it was interesting but didn't really see its relevance to either my teaching or personal practice. But my view of these exercises changed completely when I visited Houston in 1996. On this visit I studied with Master $\mathrm{Hu}$ in his home and for two weeks accompanied him to every session he ran. During this visit I had an epiphany. I saw
Master $\mathrm{Hu}$ run 2 classes that were for me eye between "eyeopening" and "jaw dropping"!

The first was a session for Cardiac Rehab patients, which he taught in a weight room at a gym; by no means an ideal setting. As I engaged in these exercises, some for the first time, I was intensely aware of not just what exercises he was using but how he implemented them. His use of rhythm, the way he slowed the pace of the exercises. The way he used pauses to enable participants to catch their breath and rest between and during exercises. The intense way he observed EVERYTHING without seeming to even be looking, so as to not give participants what he called "eyeball pressure'. Most importantly the way he used humor and music. These teaching techniques, as much as the exercises this mselves, had a profound effect on me.

The other was a seated Qigong class for seniors at a Methodist Church in a very large auditorium of the kind one sees evangelical preachers use in their sermons on TV. I watched an extraordinary Seated Qigong class with a group of seniors in Houston in which he got participants, many of whom were well over 80 , to move in ways that put my 20 year old university students to shame.

Both these events changed me. They made me completely rethink the way I taught. As a result of this experience I decided to teach seated Qigong classes. Over the next few years I taught classes primarily to people with life threatening and life changing conditions starting with Windsor -Essex Cardiac Rehab Program, then The Hospice of Windsor and more recently at various facilities for both "healthy seniors" and seniors living with chronic debilitating illnesses and dementias.

I have now been teaching, and conducting research on the benefits of, Seated Qigong for 25 years. Time to look back at what I have learned.

\section{Making Sense of the Journey}

Upon returning from Houston I did what any self respecting academic does I conducted background research; reading books, articles and research papers and watching videos on Qigong / Seated Qigong. I got hold of almost everything written in English and French, both of which I can read and in languages, notably Chinese, which I do not.

Parallel to this I started to design a seated program that I thought might work.With the help of my students and trial and error I spent some time experimenting with the exercises I saw in Houston and others that I learned from other teachers or saw in print or on video.

Some exercises I didn't understand well enough or have sufficient physical command of the motions to include in my Seated Qigong program. Some I discovered through trial and error and close observation weren't appropriate for the needs of my participants.

Eventually, in relatively short order, I developed a program of seated exercises that lasts approximately $30 \mathrm{mins}$ and employs 
tranquil music playing in the background ${ }^{2}$. I soon discovered that the new program worked MUCH better for participants. Over the years I haven't changed it much, because with minimal adaptations it can be used with most people I encounter in my classes.

How does one catch the wind? - Trying to capture the benefits of Seated Qigong

Quickly I started to see first hand the benefits for individual participants. However what benefits I had observed, or heard participants discuss, were not easy to convey. Each participant's medical, social and personal narrative was different and so the benefits they expected to receive and actually experienced were also different.

I started to think about doing research and recording the results to promote the value of what I was witnessing and experiencing first hand. I have a very good friend who is an engineer by training and a British empiricist by inclination. His wife is a Doctor and he has very little time for anything that cannot be proved by "scientific method". As he says himself, he is a man of (Western) science! Proving the benefits of Qigong to skeptics like my friend or simply to people who were not present to witness the effects is almost impossibly difficult.

When I started to consider researching seated Qigong I decided I needed to address both the quantitative dimensionthose area that might convince "men and women of science, but also the qualitative benefits of the each session. I also wanted to look not only at the short-term effects of the science (immediately pre \& post) but also whether there was any "halflife" effect of the activity.

The first research was with the participants in the Cardiac Rehab Qigong program. As with all courses offered by WECRP, blood pressure readings were taken before and after the class. For our study, participants were also asked to answer a series of questions about their health during the previous week ${ }^{3}$. In addition, immediately before and after each class participants were asked to self-report in writing (using a simple 7 point scale) about their level of pain, energy, relaxation and how they felt overall. This information was monitored on a regular basis both for each individual and for the class as a whole.

\section{What I found as a researcher}

By the time we started our research, considerable research had already been conducted concerning the benefits of Qigong and remarkable results suggested not only for persons with medical conditions (such as high blood pressure, cancer and even spinal cord injuries) but also in helping to prevent illness and increase longevity ${ }^{4}$.

Our early research showed that 30 minutes of Qigong helps normalize blood pressure, lower pulse rate and reduce stress as described by participant administered assessment scale. We discovered significant positive short-term effects of seated Qigong participants' blood pressure and sense of well-being. This early research also showed that participants reported having more energy, less illness (shorter duration and less severe) and generally felt healthier ${ }^{5}$

Later research showed Seated Qigong helps lower stress levels, reduce muscular tension and promote relaxation and most recently research conducted By Dr. Cheri McGown and I showed that Seated Qigong significantly reduces systolic blood pressure with seniors and gives a better sense of well being ${ }^{6}$.

\section{What I Learned as a Teacher}

It's the way of doing it that counts, the way of doing it, if you want to go on living?.

For Seated Qigong to be successful the leader needs to pay attention to many inter-related factors: not just the technical aspects of the exercise or set.

In my opinion this list includes paying attention to:

A. Preparation - Gather, wherever possible, detailed information on participants

B. Planning-Choose exercises suitable for the capabilities of individuals in the group

C. Environment- Choose a calm space, Play suitable music to help relax participants

D. Techniques:

a) Communication

b) Model and repeat each exercise

${ }^{2}$ For those who are interested, the program includes adapted versions of: 3 Cleansing Breaths Qigong; Balancing the Heart Qigong; Triple Warmer Qigong; \&, The Bad Duan Jin.One feature of the program was that the exercises were transportable, required no special equipment and could be done by participants on their own time at home.

${ }^{3}$ Participants were asked eight questions dealing with elements of physical health e.g. heart rate, digestion and emotional states e.g. anxiety, depression, sense of well-being

${ }^{4}$ Cohen, K (1997) The Way of Qigong: The Art and Science of Chinese Energy Healing, Ballantine Books, New York

${ }^{5}$ Warren, B \& Gervais, N (2004). Sit, Breathe And Smile: The short-term effects of Qigong on blood pressure and sense of well-being for cardiac patients. Third Global Conference: Making sense of Health, Illness and Disease. Oxford, England. July

${ }^{6}$ Shane R. Freeman; Sarah-Anne E. Hanik, BSc; Meagan L. Littlejohn; Amanda A. Malandruccolo; Joanna Coughlin, BA (Hons); Bernie Warren, PhD; Cheri L. McGowan, PhD, (2014) Sit, Breathe, Smile: Effects of Single and Weekly Seated Qigong on Blood Pressure and Quality of Life in Long-Term Care, Complementary Therapies in Clinical Practice, 20 (1), 48-53, February

${ }^{7}$ Vladimir speaking Act II, in Becket, S. (1977) Waiting for Godot, Faber, London 
c) Slow, clear Instructions- especially with Seniors

d) Use non-verbal cues where possible

e) Appropriate Pace for each exercise

f) Judicious use of "pauses' between exercises to allow participants to catch their breath

A. Frequency - What Number of repetitions of each exercise is appropriate for these participants

B. Duration- Length of each exercises and the session as a whole

C. Motivation- suitable use of jokes, comic timing, song

D. Observation:

a. Monitoring participants carefully

b. Pay particular attention to

c. Breathing Patterns

d. Any signs of adversity of distress

e. Changing the "script" as befits the needs of the participants,

My sessions are filled with music and laughter. While the program remains fairly constant I always adapt the activities, especially in terms of speed and number of repetitions to meet the needs of each group.

As I am by nature an 'improviser (as is Master $\mathrm{Hu}$ ), I often wonder whether the positive effects of my seated Qigong classes has more to do with how I teach and less to do with the exercises themselves. This is something I have been reflecting on for quite some time and maybe now that I am retired from academic teaching I may investigate this line of thought.

\section{Final thoughts}

Seated Qigong requires no expensive equipment and can be done anywhere at home, at the office or even while traveling. It provides a thorough, non-stressful and low impact work out for the whole body and because it is performed while sitting, it reduces stress on individuals for whom, and for whatever reasons, the strains of standing are difficult. It is therefore often a good choice for cardiac patients, the 'frail' elderly people, and others with physically debilitating conditions.
In my opinion, Seated Qigong can provide significant benefits for participants - especially those living with life-changing conditions. However these benefits flow not just from the exercises but also in how the exercises are presented.

Despite the difficulties of proving clinically or statistically significant benefits, especially to skeptical "men and women of science', in my opinion the benefits experienced and discussed by participants are irrefutable - at least to them. More to the point, in my opinion Seated Qigong is less likely to injure a participant with a life-changing or life-threatening condition than them taking up running or doing aerobics.

So I continue to offer Qigong to anyone and everyone who wishes to participate. If you can't find a teacher, and wish to practice Seated Qigong- just start from wherever you are. For at the end of it all doing Seated Qigong is really very simple

A. Sit comfortably-Anywhere

B. Smile

C. Breathe in - Still your mind

D. Breathe Out - Release your tensions

E. Repeat

Now, wherever you are, you are beginning to practice Seated Qigong.

\section{References}

1. Warren B, Coughlin J (2014) Stand Breathe Smile: Simple standing exercises and approaches to reduce stress and promote good health. In: Klate J S (Ed.), Tranquility Press, Oxford, UK.

2. Cohen K (1997) The Way of Qigong: The Art and Science of Chinese Energy Healing. Ballantine Books, New York, USA.

3. Warren B, Gervais N (2004) Sit, Breathe Smile: The short-term effects of Qigong on blood pressure and sense of well-being for cardiac patients. Third Global Conference: Making sense of Health, Illness and Disease. Oxford, England, p. 55-64.

4. Shane R Freeman, Sarah Anne E Hanik, Meagan L Littlejohn, Amanda A Malandruccolo, Joanna Coughlin, et al. (2014) Sit, Breathe, Smile: Effects of Single and Weekly Seated Qigong on Blood Pressure and Quality of Life in Long-Term Care, Complementary Therapies in Clinical Practice 20(1): 48-53.

5. Becket S (1977) Waiting for Godot, Faber, London, UK. 
(C) (i) This work is licensed under Creative Commons Attribution 4.0 Licens
Your next submission with Juniper Publishers will reach you the below assets

- Quality Editorial service

- Swift Peer Review

- Reprints availability

- E-prints Service

- Manuscript Podcast for convenient understanding

- Global attainment for your research

- Manuscript accessibility in different formats ( Pdf, E-pub, Full Text, Audio)

- Unceasing customer service

Track the below URL for one-step submission https://juniperpublishers.com/online-submission.php 